Journal of Computer Science and Cybernetics, V.27, N.4 (2011), 353-362

\title{
COMPUTATIONAL FLUID DYNAMICS RE-MESH METHOD TO GENERATING HYDRODYNAMIC MODELS FOR MANEUVERING SIMULATION OF TWO SUBMERGED BODIES IN RELATIVE MOTION
}

\author{
ZHI QUAN LEONG, DEV RANMUTHUGALA, IRENE PENESIS, HUNG DUC NGUYEN
}

University of Tasmania/Australian Maritime College; nguyenhd@amc.edu.au

\begin{abstract}
An Autonomous Underwater Vehicle (AUV) operating closer to a larger vessel experiences significant hydrodynamic forces requiring an adaptive control mechanism to maintain acceptable trajectory. It is therefore important that the designer understands the hydrodynamic characteristics of the vehicle in this scenario in order to develop appropriate control algorithms to deal with its dynamic behaviour. This requires developing simulations of the vehicles behaviour close to the larger vessel, the control algorithms, and the dynamic interface between the two.

This paper presents a method to generate a complete hydrodynamic model of underwater vehicles using the Computational Fluid Dynamics (CFD) code ANSYS CFX, which can then be interfaced with the vehicles control algorithms within a simulation environment. The essential aspect of the method is the re-mesh approach, where the mesh deforms locally around the bodies using an Arbitrary Lagrangian-Eulerian form of the governing fluid equations and re-meshes when the deformation significantly compromises the quality of the mesh. This overcomes the motion limitations imposed by a pure deforming mesh approach.

Preliminary work to validate the method is based on two smooth spheres moving relative to each other. It shows that this method is able to adequately simulate the fluid behaviour around the bodies. The paper also describes the future work focused on a 6 degrees-of-freedom (6-DOF) AUV modelled in CFD to obtain its hydrodynamic behaviour to be interfaced to the control system within MATLAB.
\end{abstract}

Tóm tắt. Một phương tiện ngầm tự hành (AUV) hoạt động gần tới một tầu lớn hơn chịu ảnh hường các lực thủy động học đáng kể cần một cơ cấu điều khiển thích nghi để duy trì quỹ đạo chuyển động ở mức cho phép. Do vậy điều quan trọng là người thiết kế biết được các đặc tính thủy động học của phương tiện ngầm trong tình huống này để có thể phát triền các thuật toán điều khiển thích hợp với động thái của nó. Điều này đòi hỏi việc phát triển các mô phỏng động thái của phương tiện ngầm khi hoạt động gần một tầu lớn hơn, các thuật toán điều khiển và tương tác động học giữa hai vật thề.

Bài báo này trình bày phương pháp tạo ra một mô hình thủy động học trọn vẹn của các phương tiện ngầm sử dụng phần mềm ANSYS CFX gói mã Động học Chất lơng Tính toán $(\mathrm{CFD})$, và có thề tương tác mô hình này với các thuật toán điều khiển phương tiện ngầm trong môi trường mô phỏng. Điểm chính yếu của phương pháp là cách tái thiết lập mạng tại đó mạng biến dạng cục bộ xung quanh các vật thể dùng phương trình chất lỏng mô tả có dạng Lagrangian-Eulerian tự chọn và tái thiết lập mạng khi sự biến dạng có ảnh hường rất đáng kể đến chất lượng của mạng. Phương pháp này khắc phục được những hạn chế gây ra bởi phương pháp biến dạng mạng thuần túy.

Việc đánh giá phương pháp sơ bộ ban đầu được dựa trên hai mặt trơn tru chuyển động tương 
đối với nhau. Qua đó cho thấy phương pháp này có thể mô phỏng đầy đủ động thái chất lỏng xung quanh các vật thể. Bài báo này cũng trình bày các công việc tiếp theo tập trung vào một phương tiện ngầm sáu bậc tự do (6-DOF) được mô hình hóa trong phần mềm CFD để thu được động thái thủy động học tương tác với hệ thống điều khiển trong môi trường MATLAB.

\section{Nomenclature}

$F_{s}, F_{b}:$ Stable and apparent body forces;

$X_{C F D}, Y_{C F D}, Z_{C F D}$ : Force vector obtained from integrated body surface pressure and shear;

$K_{C F D}, M_{C F D}, N_{C F D}$ : Moment vector obtained from integrated body surface pressure and shear;

$X_{S}, Y_{S}, Z_{S}:$ Weight and buoyancy vectors;

$X_{P}, Y_{P}, Z_{P}$ : Thrust vector obtained from the propulsion system model;

$K_{P}, M_{P}, N_{P}$ : Torque/moment obtained from the propulsion system model;

$x, y, z:$ Body axis coordinates;

$u, v, w$ : Linear velocities;

$p, q, r:$ Angular velocities;

$\dot{u}, \dot{v}, \dot{w}$ : Linear accelerations;

$S:$ Static stability forces;

$B$ : Centre of buoyancy;

$G:$ Centre of mass;

$O:$ Inertial coordinate system;

$R, r$ : Position vector;

$I$ : Moments and products of inertia for body;

$\rho$ : Fluid density;

$t$ : Time;

$\phi, \theta, \psi:$ Roll, pitch, and yaw;

$W:$ Net Buoyancy Force;

Re : Reynolds Number (based on diameter);

\section{Abbreviation}

Computation Fluid Dynamics (CFD), Degree of Freedom (DOF), Autonomous Underwater Vehicle (AUV), Arbitrary Lagrangian-Eulerian (ALE).

\section{INTRODUCTION}

When an AUV is operating close to a larger vessel such as a submarine or a surface ship, the hydrodynamic interactions between the two can be significant (Fig. 1). Given that the AUV is relatively small, this interaction can adversely affect its trajectory, which in extreme cases can cause collision or loss of the vehicle. Therefore, it is essential that the AUVs control system is sufficiently robust and adaptive to deal with rapidly varying pressure and velocity fields around the vehicle (Fig. 2). 
In order to quantify the interaction between the two vehicles, it is required to conduct numerical and/or experimental work to obtain their hydrodynamic characteristics during operations in close proximity. One method of numerically obtaining this is to conduct CFD simulations of the vehicle manoeuvres to predict the resulting forces and moments, which will characterise the behaviour of the vehicles. This can then be fed into the control system simulation to develop the necessary algorithms to maintain the required trajectory.

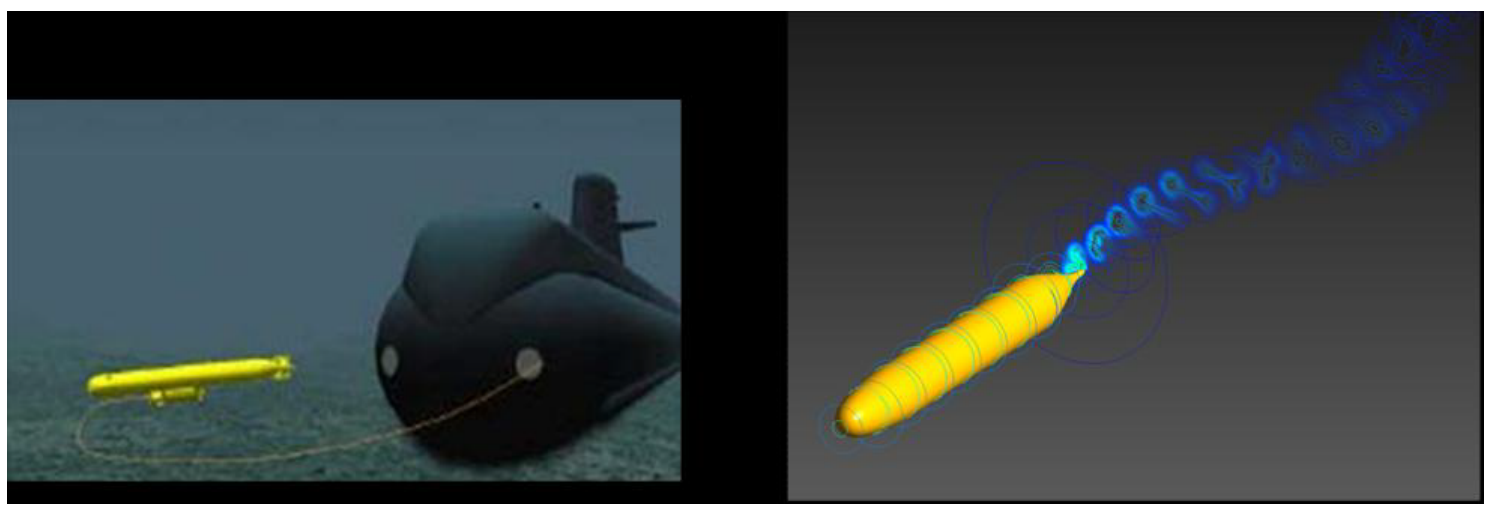

Fig. 1.

Fig. 2.

Fig. 1. Interaction between vehicles (ROV-online.com). Fig. 2. Velocity field around an AUV.

To date, many of the numerical approaches to obtain the hydrodynamic characteristics of multiple submerged vehicles adopt a body fixed mesh ([3] and [4]), where the fluid domain mesh is rigid and the bodies are held at fixed locations relative to the fluid domain. Flow is initiated at the fluid domain boundaries to provide relative motion between the fluid and the bodies in the required directions (Fig. 3). This approach has proven successful in predicting the hydrodynamic forces and moments on multiple bodies that are at fixed locations. However, this approach is not suitable when the bodies move relative to each other. In addition, it fails to incorporate the acceleration and added mass components of the bodies and the surrounding fluid.

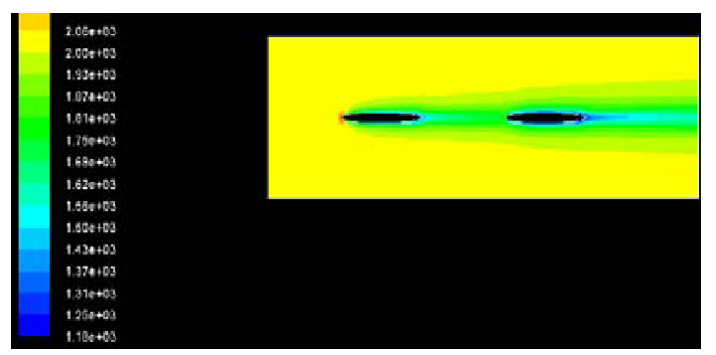

Fig. 3. Body fixed mesh simulation [4]

This project recommends an alternate approach using the ANSYS Meshing Platform (AMP) re-mesh method, which is currently a beta feature within the ANSYS v13.0 CFD code. The method theoretically allows an arbitrary number of bodies in relative motion to be simulated, where the mesh deforms locally around the bodies during motion and re-meshes when the deformation significantly compromises the quality of the mesh (Note: an example 
of CFD mesh used in the current simulation is shown in Fig. 6). However, the capability of the method is yet to be validated for such simulations and studies adopting the method are currently non-existent in the public domain. Hence, the objective of this paper is to:

+ Present the underlying theory behind the re-mesh method and its implementation for 6-DOF simulations;

+ Outline the solution procedure of the simulation; and

+ Provide preliminary results of the method in terms of accuracy.

\section{FLUID EQUATIONS OF MOTION}

The CFD re-mesh method requires an Arbitrary Lagrangian-Eulerian (ALE) form of the governing fluid equations to accommodate the deformation in the mesh. The ALE formulation allows the mesh motion to be defined independent of the motion of the fluid being analysed.

The mass momentum equations in ALE form are as shown below, where calculation of the mesh velocity umj is based on the domain boundary movement of the body [1].

Mass conservation:

$$
\frac{\partial \rho}{\partial t}+\frac{\partial \rho\left(u_{j}-u_{m j}\right)}{\partial x_{j}}=0
$$

Momentum:

$$
\frac{\partial \rho u_{i}}{\partial t}+\frac{\partial \rho u_{i}\left(u_{j}-u_{m j}\right)}{\partial x_{j}}=F_{s}+F_{b}
$$

where stable forces on the body $\left(F_{s}\right)$ is

$$
F_{s}=\frac{\partial p}{\partial x_{i}}+\frac{\partial}{\partial x_{j}}\left(\mu \frac{\partial u_{i}}{\partial x_{j}}\right),
$$

and the apparent body force $\left(F_{b}\right)$ is

$$
F_{b}=-\rho \frac{d_{0}^{2} R}{d t^{2}}
$$

To account for the deforming mesh, the turbulence equations are also in ALE form: $k$ - equation:

$$
\frac{\partial \rho k}{\partial t}+\frac{\partial \rho k\left(u_{j}-u_{m j}\right)}{\partial x_{j}}=P_{k}-\beta^{\prime} \rho k \omega+\frac{\partial}{\partial x_{j}}\left[\left(\mu+\frac{\mu_{t}}{\sigma_{k}}\right) \frac{\partial k}{\partial x_{j}}\right] .
$$

$\omega$ - equation:

$$
\frac{\partial \rho \omega}{\partial t}+\frac{\partial \rho \omega\left(u_{j}-u_{m j}\right)}{\partial x_{j}}=\alpha \frac{\omega}{k} P_{k}-\beta^{\prime} \rho k \omega^{2}+\frac{\partial}{\partial x_{j}}\left[\left(\mu+\frac{\mu_{t}}{\sigma_{\omega}}\right) \frac{\partial \omega}{\partial x_{j}}\right] .
$$

Details on the turbulence model source terms are available in [1]. An additional set of mesh displacement Laplace equations is added to solve the ALE formulation. The Laplace equations diffuse boundary motion into the interior of the fluid domain. The resulting solution, obtained 
by integrating over the time interval, allows for the extraction of the mesh velocity $u_{m j}$. The set of Laplace equations is as follows:

Mesh displacement equations:

$$
\frac{\partial \rho}{\partial x_{j}}\left(\Gamma \frac{\partial x_{i}^{\prime}}{\partial x_{j}}\right)=0
$$

where

$$
x_{i}^{\prime}=x_{i}-x_{i}^{0} .
$$

The displacement diffusion coefficient, $\Gamma$, is a function of near wall distance.

\section{BODY EQUATIONS OF MOTION}

The set of equations described below is used to illustrate the coupling of the body equations of motion with the fluid equations of motion in ALE form for a 6-DOF simulation [2]. The body equations of motions, based on a translating coordinate system fixed to a submerged body and are as follows:

General equation of motion:

$$
\begin{gathered}
\sum F=m \dot{u}_{G}, \\
\dot{u}_{G}=\left(\dot{u}_{0}\right)_{x y z}+\dot{\omega} r_{G}+\omega\left(\omega r_{G}\right), \\
\sum M_{0}=([\dot{I}] \omega+[\dot{I}] \alpha)_{x y z}+r_{G} m \dot{u}_{G} .
\end{gathered}
$$

The moments of inertia are functions of time and evaluated at each new time interval where,

$$
[\dot{I}] \omega+[I] \alpha)=\frac{d([I] \omega)}{d t} .
$$

This allows a system of equations to be solved to track the motion of the body, where axial $(x$-axis), lateral ( $y$-axis), and normal ( $z$-axis) forces are,

$$
\begin{aligned}
& m\left[\dot{u}-x_{G}\left(q^{2}+r^{2}\right)+y_{G}(p q-\dot{r})+z_{G}(p r+\dot{q})\right]=X_{C F D}+X_{S}+X_{P}, \\
& m\left[\dot{v}-y_{G}\left(r^{2}+p^{2}\right)+z_{G}(q r-\dot{p})+x_{G}(q p+\dot{r})\right]=Y_{C F D}+Y_{S}+Y_{P}, \\
& m\left[\dot{w}-z_{G}\left(p^{2}+q^{2}\right)+x_{G}(r p-\dot{q})+y_{G}(r q+\dot{p})\right]=Z_{C F D}+Z_{S}+Z_{P},
\end{aligned}
$$

with the force vectors obtained from the stable and apparent forces. Similarly rolling ( $x$-axis), pitching ( $y$-axis) and yawing ( $z$-axis) moment are,

$$
I_{x} \dot{p}-I_{z x} \dot{r}-I_{x y} \dot{q}-\dot{I}_{x} p-\dot{I}_{z x} r-\dot{I}_{x y} q+m\left[y_{G} \dot{w}-Z_{G} \dot{v}\right]=K_{C F D}+K_{S}+K_{P},
$$




$$
\begin{gathered}
I_{y} \dot{q}-I_{x y} \dot{p}-I_{y z} \dot{r}+\dot{I}_{y} q-\dot{I}_{x y} p-\dot{I}_{y z} r+m\left[z_{G} \dot{u}-x_{G} \dot{w}\right]=M_{C F D}+M_{S}+M_{P}, \\
I_{z} \dot{r}-I_{y z} \dot{q}-I_{z x} \dot{p}+\dot{I}_{z} r-\dot{I}_{y z} q-\dot{I}_{z x} p+m\left[x_{G} \dot{v}-y_{G} \dot{u}\right]=N_{C F D}+N_{S}+N_{P} .
\end{gathered}
$$

This results in a matrix system:

$$
\left[\begin{array}{cccccc}
m & 0 & 0 & 0 & m z_{G} & -m y_{G} \\
0 & m & 0 & -m z_{G} & 0 & m x_{G} \\
0 & 0 & m & m y_{G} & -m x_{G} & 0 \\
0 & -m Z_{G} & m y_{G} & I_{x} & -I_{x y} & -I_{z x} \\
m Z_{G} & 0 & -m x_{G} & -I_{x y} & I_{y} & -I_{y z} \\
-m y_{G} & m x_{G} & 0 & -I_{z x} & -I_{y z} & I_{z}
\end{array}\right]\left[\begin{array}{c}
\dot{u} \\
\dot{v} \\
\dot{w} \\
\dot{p} \\
\dot{q} \\
\dot{r}
\end{array}\right]=\left[\begin{array}{c}
X_{R H S}-X_{L H S} \\
Y_{R H S}-Y_{L H S} \\
Z_{R H S}-Z_{L H S} \\
K_{R H S}-K_{L H S} \\
M_{R H S}-M_{L H S} \\
N_{R H S}-N_{L H S}
\end{array}\right] .
$$

The solution of the matrix system results in estimates at the new time level of accelerations $(\dot{u}, \dot{v}, \dot{w}, \dot{p}, \dot{q}, \dot{r})$, which in turn with the known time step allow for calculation of velocities $(u, v, w, p, q, r)$.

The auxiliary derivatives in the inertial frame $\left(\dot{x}_{0}, \dot{y}_{0}, \dot{z}_{0}, \dot{\phi}, \dot{\theta}, \dot{\psi}\right)$ is then integrated to obtain the new position and angular movement $\left(x_{0}, y_{0}, z_{0}, \phi, \theta, \psi\right)$.

\section{IMPLEMENTATION AND SOLUTION PROCEDURE}

\subsection{CFX re-mesh method}

The essential aspect of the method is that the mesh in the fluid domain deforms locally around the body as it moves, and re-meshes when the mesh quality is deemed poor. The simulation information from the previous mesh is interpolated into the new mesh. This allows the bodies within the fluid domain to move in relative motion, which is not possible using a body fixed mesh approach.

Re-meshing within the ANSYS code can be carried out either through the AMP or ICEM CFD mesher. ICEM CFD re-meshing option exists as a built-in feature within ANSYS v13.0. However, its re-meshing is tied to the original mesh parameters, and thus requires a high quality robust mesh to prevent compromising the mesh integrity during the re-mesh process. This in turn requires significant mesh development time, while slowing down the simulation runtime.

The AMP re-meshing option is able to use a much simpler mesh and offers an automated re-meshing approach suitable for most complex geometries. In addition, the method offers more control over the geometry and meshing parameters during the solving stage. However, the method is yet to be fully integrated into the ANSYS code and requires a user defined re-meshing script to transfer the motion of the bodies into ANSYS WorkBench (WB) in order to recreate the geometry and new mesh. The user-defined script is summarized into five main parts (as shown in Fig. 4):

Part 1: Opens WB project component.

Part 2: Extract monitor data from the current time step. 
Part 3: Override values of WB parameters for the geometry and mesh based on monitor data. Part 4: Recreate geometry and mesh.

Part 5: Replace mesh, interpolate solution on new mesh, and continue solver run.

The interrupt conditions, e.g. mesh quality below a predetermined threshold, to initiate re-meshing script is defined in the solver control.

\subsection{Solution process}

The solution procedure involves iterating within a time step to obtain the average force and moment conditions over the time step that result in a new predicted velocity state for the next time step.

Within a time step, the hydrodynamic variables are recomputed providing a new set of forces and moments to use in the body equations of motion. The repetition of the iterations (coefficient loops) and re-evaluation of the body state is continued until the RMS residuals in the fluid equations are reduced below a specified limit. The solution process is summarized in the flowchart shown in Fig. 5.

\section{RESULTS}

The current development work focuses on the re-mesh method. The coupling of the fluid equations of motion with the body equations of motion as described in Section 3 and Section 4 is also examined using ANSYSs built-in rigid body solver. This will be incorporated in future work which involves coupling the fluid and body equations with a control system to simulate a full 6-DOF AUV manoeuvring close to a larger vessel. The simulations presented in this paper examine the accuracy of the re-mesh method to predict the flow around the bodies under a prescribed motion, and the acceleration of the motions when coupled with the rigid body solver

To validate the re-mesh method, two identical smooth spheres are considered as shown in Fig. 6. All simulation cases were carried out in RANS mode using the Shear Stress Transport (SST) turbulence model, which is able to adequately model both the near wall and free stream conditions. Two simulation cases are described below.

Simulation case 1 (Prescribed motion)

Two spheres, Sphere 1 and Sphere 2, are to maintain position parallel to a free stream of $R e=1 \times 10^{4}$ for 2 seconds. Sphere 2 maintains position throughout simulation to serve as a control. At simulation time, $t=2 \mathrm{~s}$, Sphere 1 moves forward in the $x$-direction under a prescribed acceleration, increasing at a rate of $0.179 \mathrm{~m} / \mathrm{s}^{2}$ per second, for 2.5 seconds. A fixed time step of $0.01 \mathrm{~s}$ was used.

The spheres are $0.1 \mathrm{~m}$ in diameter, with neutral buoyancy in order to isolate the need for the body equations of motion.

The $X$ forces on the two spheres plotted in comparison to the experimental results by Morrison [5] are shown in Fig. 7 and Fig. 8. As seen by the results, the general trend is well replicated. However, there are some issues in capturing certain aspects of the force curve, such as the 'dip experienced in Morrisons curve for the moving sphere as its velocity increases and 
the boundary layers transits from laminar to turbulent. This will require further refinement to the mesh and the model settings.

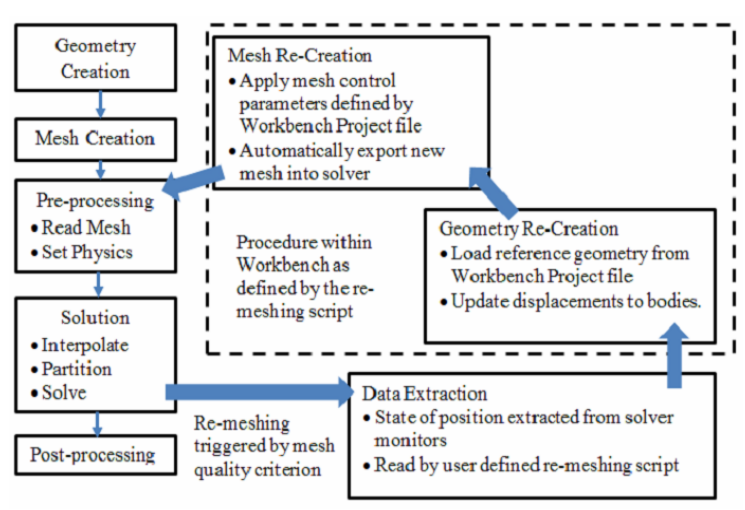

Fig. 4. Flowchart of the AMP re-meshing process

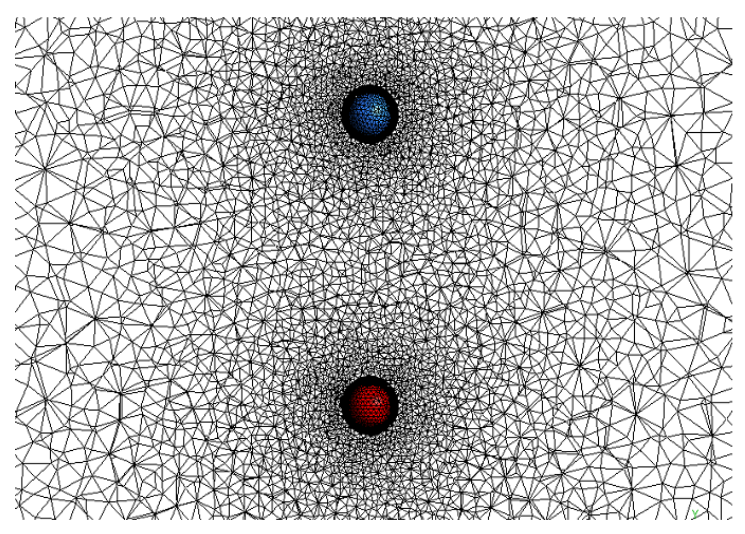

Fig. 6. Mesh of two spheres (re-mesh)

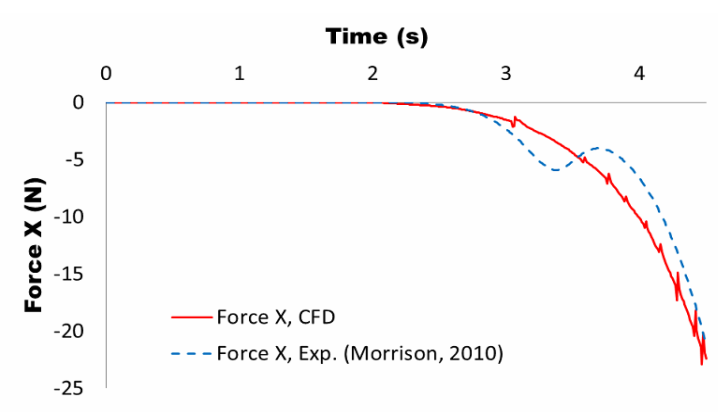

Fig. 7. Sphere 1 (moving) - compute force $X$

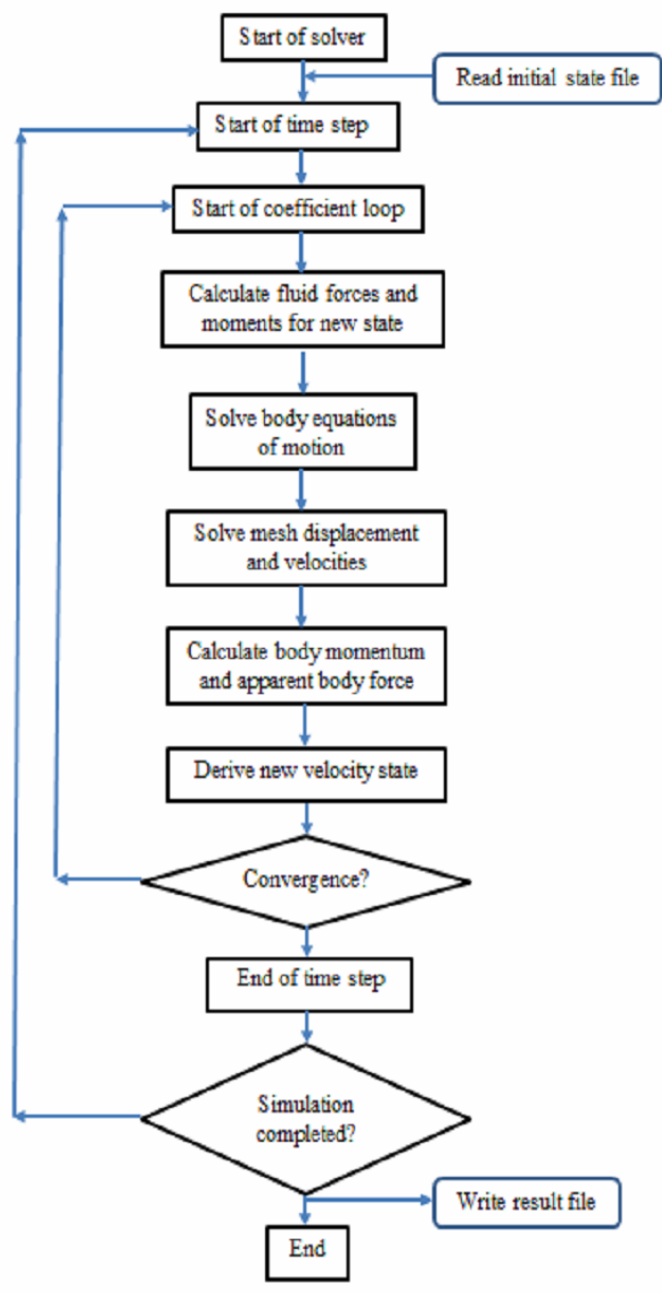

Fig. 5. Flowch art of the sd ution procedure

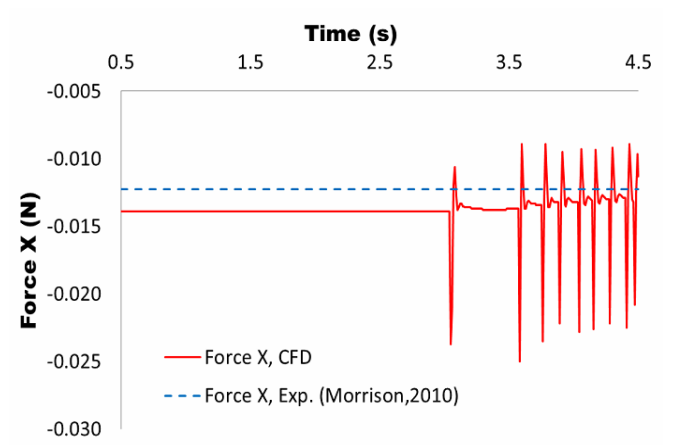

Fig. 8. Sphere 2 (stationary) - compute force $X$ 
The CFD forces on the stationary body in Fig. 8 are relatively close to the experimental results. The spike exhibited in the CFD results represents the re-meshing, as the solver has to re-establish convergence. It is observed that the re-meshing introduces a small discontinuity in the force which can be reduced through time step refinement and increasing the coefficient loops.

Simulation case 2 (Rigid body solver)

In this case, full coupling between the CFD solution and ANSYS rigid body solver is used. Both Sphere 1 and Sphere 2 are $10 \mathrm{~m}$ apart to isolate out any interaction between the bodies, and are submerged at an initial depth of $100 \mathrm{~m}$. The spheres are then allowed to float upwards for 1.5 seconds in order to examine the accelerations of the spheres as a result of buoyancy.

The spheres are $1 \mathrm{~m}$ in diameter, with buoyancy and gravity (in the z-direction) activated. The mass, added mass, and moments of inertia for the spheres are shown in Table 1. It is noted that the added mass for a sphere is constant in the $x, y$, and $z$ directions and zero in the angular directions.

Table 1. Mass and inertia properties of the spheres

\begin{tabular}{|l|l|l|}
\hline & Sphere 1 & Sphere 2 \\
\hline Mass [kg], m & 261.014 & 391.521 \\
\hline$I_{x}\left[\mathrm{~kg} \mathrm{~m}^{2}\right]$ & 26.1014 & 39.1521 \\
\hline$I_{y}\left[\mathrm{~kg} \mathrm{~m}^{2}\right]$ & 26.1014 & 39.1521 \\
\hline$I_{z}\left[\mathrm{~kg} \mathrm{~m}^{2}\right]$ & 26.1014 & 39.1521 \\
\hline Added Mass $[\mathrm{kg}], m_{a}$ & 261.014 & 261.014 \\
\hline
\end{tabular}

The net buoyancy force, $W$, is obtained by subtracting the weight from the buoyancy force of the spheres. Using the Newtons $2^{\text {nd }}$ law, the linear accelerations of the spheres in the negative $z$-direction (i.e. upwards) are analytically obtained as,

$$
\dot{w}=-\frac{W}{m+m_{a}} .
$$

The displacements in the $z$-direction are obtained by twice integrating Eq. (20) with respect to time as,

$$
z(t)=-\frac{0.5 W}{m+m_{a}} t^{2}
$$

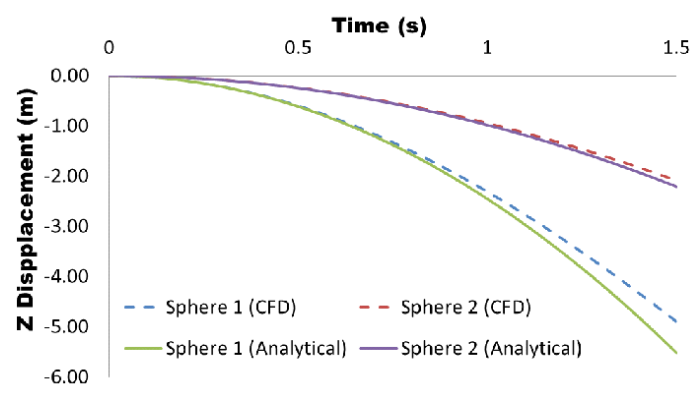

Fig. 9. Z-displacement of Sphere 1 and Sphere 2 
The predicted CFD (upward) acceleration for Sphere 1 is $4.741 \mathrm{~m} / \mathrm{s}^{2}$ while the analytical result is $4.905 \mathrm{~m} / \mathrm{s}^{2}$, giving an error of $3.34 \%$. For Sphere 2, the predicted acceleration is 1.902 $\mathrm{m} / \mathrm{s}^{2}$ with the analytical result being $1.962 \mathrm{~m} / \mathrm{s}^{2}$, thus having an error of $3.04 \%$. Fig. 9 shows the $z$-displacement of the two spheres plotted in comparison to the analytical results. As seen by the results, the general trend is well replicated.

\section{CONCLUSIONS}

AUVs operating close to larger surface and submerged vessels will require simulations of both the hydrodynamic behaviour and the adaptive control system to enable proper design of the vehicle. The two components of the simulation need to be interfaced to enable the designer to understand the response of the vehicle due to the interaction between the AUV and the vessel.

The paper described the simulation of two underwater bodies moving relative to each other to provide hydrodynamic data to feed into the AUV control system simulation. Initially this consisted of two spheres. However, this will be expanded to simulate a fully appended 6-DOF AUV and a submerged moving vessel. In general, an AUV is a complex geometry due to the appendages. Therefore, it is foreseen that the AUV mesh model will require significant refinement, thus resulting in greater development effort and longer runtime during the simulations. The process employed is the AMP re-meshing method in ANSYS-CFX, which was coupled with a rigid body solver to predict the accelerations of the bodies. The simulations provided promising results in comparison to experimental data and analytical results. This method is currently being improved to provide faster real time data linked to a MATLAB control environment replicating the AUVs control algorithm.

\section{REFERENCES}

[1] ANSYS. ANSYS CFX user manual, 2011.

[2] S. Dajka, P. Godin, and A. Gerber, Software design documentation for a six-dof unsteady simulation capability in ANSYS-CFX, DRDC, Canada. 2007.

[3] M. Hussani, Z. Samad, and M.R. Arshad, CFD simulation of cooperative AUV motion, Indian Journal of Marine Sciences 38 (2009) 346-351.

[4] P. Jagedeesh, RANS prediction for drag characteristics over cooperative axisymmetric bodies, International Journal of Earth Sciences and Engineering 4 (2011) 628-631.

[5] F.A. Morrison, "Data correlation for drag coefficient for sphere", Michigan Technology University, Houghton, MI. 2010.

Received on January 30 - 2012 